\title{
In situ x-ray absorption spectroscopy study of hydrogen absorption by nickel-magnesium thin films
}

\author{
B. Farangis, ${ }^{1}$ P. Nachimuthu, ${ }^{2,3}$ T. J. Richardson, ${ }^{1 *}$ J. L. Slack, ${ }^{1}$ R. C. C. Perera, ${ }^{2}$ \\ E. M. Gullikson, ${ }^{2}$ D. W. Lindle, ${ }^{3}$ and M. Rubin ${ }^{1}$ \\ ${ }^{1}$ Environmental Energy Technologies Division \\ ${ }^{2}$ Center for X-ray Optics, Materials Sciences Division \\ Lawrence Berkeley National Laboratory \\ 1 Cyclotron Road, Berkeley, CA 94720 \\ ${ }^{3}$ Department of Chemistry \\ University of Nevada, \\ Las Vegas, NV 89154
}

July 2002

This work was supported by the Assistant Secretary for Energy Efficiency and Renewable Energy, Office of Building Technology, State and Community Programs, Office of Building Research and Standards of the U.S. Department of Energy under Contract No. DE-AC03-76SF00098. The Advanced Light Source is operated by the Director, Office of Science, Office of Basic Energy Sciences, Division of Materials Science of US Department of Energy under Contract No. DE-AC03-76SF00098 at LBNL. Financial support from the National Science Foundation under contract Nevada-NSF-EPSCoR is gratefully acknowledged. 


\title{
In situ x-ray absorption spectroscopy study of hydrogen absorption by nickel-magnesium thin films
}

\author{
B. Farangis, *P. Nachimuthu, T. J. Richardson, ${ }^{*}$ J. L. Slack, R. C. C. Perera, \\ E. M. Gullikson, M. Rubin \\ Lawrence Berkeley National Laboratory \\ D. W. Lindle \\ *University of Nevada
}

Structural and electronic properties of co-sputtered $\mathrm{Ni}-\mathrm{Mg}$ thin films with varying $\mathrm{Ni}$ to $\mathrm{Mg}$ ratio were studied by in-situ X-ray absorption spectroscopy in the Ni L-edge and $\mathrm{Mg} \mathrm{K}$-edge regions. Co-deposition of the metals led to increased disorder and decreased coordination around $\mathrm{Ni}$ and $\mathrm{Mg}$ compared to pure metal films. Exposure of the metallic films to hydrogen resulted in formation of hydrides and increased disorder. The presence of hydrogen as a near neighbor around $\mathrm{Mg}$ caused a drastic reduction in the intensities of multiple scattering resonances at higher energies. The optical switching behavior and changes in the X-ray spectra varied with $\mathrm{Ni}$ to $\mathrm{Mg}$ atomic ratio. Pure $\mathrm{Mg}$ films with $\mathrm{Pd}$ overlayers were converted to $\mathrm{MgH}_{2}$ : the $\mathrm{H}$ atoms occupy regular sites as in bulk $\mathrm{MgH}_{2}$. Although optical switching was slow in the absence of $\mathrm{Ni}$, the amount of $\mathrm{H}_{2}$ absorption was large. Incorporation of $\mathrm{Ni}$ in $\mathrm{Mg}$ films led to an increase in the speed of optical switching but decreased maximum transparency. Significant shifts in the $\mathrm{Ni} \mathrm{L}_{3}$ and $\mathrm{L}_{2}$ peaks are consistent with strong interaction with hydrogen in the mixed films.

*tjrichardson@lbl.gov

PACS: 61.10.Ht, 78.20.-e, 78.66.-w, 82.30.-b 


\section{INTRODUCTION}

Switchable mirrors exhibiting variable optical, mechanical and electrical properties due to uptake and removal of hydrogen were discovered by Huiberts et al. ${ }^{1}$ They have significant potential for applications in light and heat regulation, display devices, and optical communication systems. The first generation of switchable mirrors was based on rare earth metals which undergo a reversible metal-insulator transition when thin films coated with palladium are exposed to $\mathrm{H}_{2}{ }^{2}$ Van der Sluis et al. ${ }^{3}$ reported that incorporation of magnesium increased the transparency of lanthanide hydride films. The larger optical band gap $(3.4 \mathrm{eV})$ for $\mathrm{Gd}_{0.5} \mathrm{Mg}_{0.5} \mathrm{H}_{2.5}$ makes this switchable mirror colorless in contrast to reddish $\mathrm{GdH}_{3}$. Recently Richardson et al. ${ }^{4,5}$ reported switchable mirror effects in thin films of $\mathrm{Mg}$ and $3 \mathrm{~d}$ transition metals ( $\mathrm{Ni}, \mathrm{Mn}, \mathrm{Fe}$, and $\mathrm{Co}$ ). These are potentially more cost effective since they do not require the expensive and reactive rare earth metals.

A recent report ${ }^{6}$ on the hydrogenation of $200 \mathrm{~nm}$ thick $\mathrm{Mg}$ films with Pd overlayers by $\mathrm{H}_{2}$ gas at $0.1 \mathrm{MPa}$ and $100^{\circ} \mathrm{C}$ showed that magnesium hydride is formed, with $\mathrm{H}_{2}$ loading ranging from 2.9 to $6.6 \mathrm{wt} . \%$. After $24 \mathrm{~h}$, transparent magnesium hydride was obtained. $^{7}$ The temperature required for dehydrogenation decreased with decreasing degree of crystallization. Heating the hydride film led to the formation of nano-structured magnesium. $\mathrm{H}_{2}$ absorption leads to lattice expansion and structural rearrangements, which modify the electronic properties of the films.

Near-edge $x$-ray absorption fine structure (NEXAFS) and extended x-ray absorption fine structure (EXAFS) are powerful tools for understanding the electronic and structural properties of thin films. ${ }^{8-10}$ These techniques are element-specific and capable of probing the short to medium range structure around an absorbing atom. Among the experimental techniques employed in determining the valence states of atoms in solids, NEXAFS plays a crucial role due to its simplicity and universal applicability. EXAFS is sensitive to the local structure around an atom, and is especially useful in studying amorphous materials.

X-ray absorption spectroscopy (XAS) and X-ray magnetic circular dichroism (XMCD) are used to study the electronic and magnetic properties of $3 d$ elements. Theoretical and experimental studies have shown that the band structure of bulk $\mathrm{Ni}$ is 
different from that of $\mathrm{Ni}$ thin films grown on $\mathrm{Cu}$ and Co. ${ }^{11-14}$ This results in different electronic and magnetic properties. The line shapes of XAS and XMCD spectra can change dramatically for varying film thickness due to electron transfer and hybridization at the interface or due to $3 d$ electron correlation effects. ${ }^{15}$ Srivastava et al. ${ }^{16}$ have shown that the thickness dependent density of $3 d$ holes for $\mathrm{Ni}$ thin films grown on $\mathrm{Cu}(001)$ gives rise to a modified XAS line shape. Therefore a detailed analysis of $\mathrm{Ni}_{2,3}$ edges (which is a direct measure of unoccupied d states) and $\mathrm{Mg} \mathrm{K}$-edge are a useful approach to study the electronic structure of our samples in the metallic and hydride state.

Here we report an investigation of the structural and electronic properties of $\mathrm{Ni}$ $\mathrm{Mg}$ thin films with varying $\mathrm{Ni}$ to $\mathrm{Mg}$ atomic ratio using in-situ x-ray absorption spectroscopy. The mirror-like metallic Ni-Mg thin films become optically transparent due to $\mathrm{H}_{2}$ absorption. We followed the hydrogenation processes by recording $\mathrm{x}$-ray absorption spectra at both the $\mathrm{Mg} \mathrm{K}$ and Ni L-edges.

\section{Experimental Procedure}

\section{Sample preparation}

$\mathrm{Ni}-\mathrm{Mg}$ films for the present study were prepared by dc magnetron co-sputtering from $50 \mathrm{~mm} \mathrm{Ni}$ and $\mathrm{Mg}(99.98 \%)$ targets inclined $22.5^{\circ}$ from normal onto silicon nitride membrane substrates (Silson Ltd., Northampton, UK), which were mounted sequentially on a glass plate to obtain different $\mathrm{Ni}$ to $\mathrm{Mg}$ atomic ratios. The base pressure was $1.4 \times 10^{-7}$ Torr, process pressure 2 mTorr, Ni power $24 \mathrm{~W}, \mathrm{Mg}$ power $47 \mathrm{~W}$, target-to-substrate distance $7.5 \mathrm{~cm}$. Deposition rates ranged from 0.33 to $0.55 \mathrm{~nm} / \mathrm{s}$, depending on location of the substrate. Palladium was deposited over all Ni-Mg films to protect them from air oxidation and to promote absorption of hydrogen. The Pd over-layer was applied at 10 mTorr, Pd power $12.4 \mathrm{~W}$, with deposition rate $0.16 \mathrm{~nm} / \mathrm{s}$. Film thicknesses and compositions were measured by stylus profilometry and Rutherford back scattering (RBS). $\mathrm{Mg}_{2} \mathrm{Ni}$ (containing $20 \%$ excess $\mathrm{Mg}$ ) was purchased from Ergenics, Inc., (Ringwood, $\mathrm{NJ}$ ) and $\mathrm{MgH}_{2}$ (nominal purity $90 \%$, remainder $\mathrm{Mg}$ ) from Aldrich Chemical Co, (Milwaukee, WI). Powder x-ray diffraction patterns (xrd) for these compounds confirmed their bulk compositions and purity. 
$X$-ray absorption measurements

The x-ray absorption spectra were measured at beamlines 6.3.1 and 6.3.2 at the Advanced Light Source, Lawrence Berkeley National Laboratory. ${ }^{17}$ During the measurements, the synchrotron was typically operated at $1.9 \mathrm{GeV}$ between 200 and 400 $\mathrm{mA}$. The spectra were recorded at the $\mathrm{Mg} \mathrm{K}$ and $\mathrm{Ni} \mathrm{L}$ absorption edges in the bulksensitive transmission detection mode, in an atmosphere of He using a 4.6x4.6 mm photodiode detector (Hamamatsu, G1127-02). Hydrogenation of the films was achieved by purging with $4 \% \mathrm{H}_{2}$ in $\mathrm{He}$. The spectra for reference materials $\mathrm{Mg}_{2} \mathrm{Ni}$ and $\mathrm{MgH}_{2}$ were measured by total fluorescence yield (TFY) using a 28x28 mm windowless detector (Hamamatsu, S3584-06). The resolution at the Mg K and Ni L-edges was better than 1.5 and $1.0 \mathrm{eV}$, respectively. The photon energy was calibrated to the first inflection point of the $\mathrm{Ni}_{3}$ edge at $852.7 \mathrm{eV}$ and $\mathrm{Mg} \mathrm{K}$ edge at $1303.0 \mathrm{eV} .{ }^{18}$ After calibration, the spectra were normalized to the absorption edge jumps. ${ }^{8}$ All measurements were performed at room temperature.

\section{Results and Discussion}

Previous work $^{3}$ on $\mathrm{Ni}-\mathrm{Mg}$ thin films showed that the $\mathrm{Ni}$ to $\mathrm{Mg}$ atomic ratio and the film thickness are factors in determining the speed at which switching takes place between the metallic state and the transparent hydride state. The freshly sputtered films were amorphous by xrd, showing only weak reflections due to Pd. Co-deposition from offset sources yielded films with position-dependent $\mathrm{Ni}-\mathrm{Mg}$ atomic ratio and thickness (Table I). They absorbed hydrogen rapidly and reached maximum transparency within a few minutes. When samples were annealed at $125{ }^{\circ} \mathrm{C}$ in dry nitrogen, xrd reflections due to $\mathrm{Mg}_{2} \mathrm{Ni}, \mathrm{Mg}$, and $\mathrm{Mg}_{6} \mathrm{Pd}$ developed. The annealed films did not take up $\mathrm{H}_{2}$ readily.

Ni $L_{3,2}$-edge NEXAFS

$\mathrm{Ni} \mathrm{L}_{3,2}$-edge $\mathrm{x}$-ray absorption spectra measured in transmission mode in $\mathrm{He}$ and in $4 \% \mathrm{H}_{2}$ (balance $\mathrm{He}$ ) for a pure $\mathrm{Ni}$ film and two Ni-Mg films are shown in Fig. 1. The spectrum for $\mathrm{Mg}_{2} \mathrm{Ni}$ powder measured by total fluorescence yield is included for comparison. The transitions denoted as $\mathrm{L}_{3}$ and $\mathrm{L}_{2}$, at $\sim 853.5 \mathrm{eV}$ and $\sim 870.8 \mathrm{eV}$, are from $\mathrm{Ni} 2 \mathrm{p}_{3 / 2}$ and $2 \mathrm{p}_{1 / 2}$ to $3 \mathrm{~d}$ final states, respectively. ${ }^{15,18,19}$ Satellites at $\sim 3 \mathrm{eV}$ and $\sim 6 \mathrm{eV}$ above the $\mathrm{L}_{3}$-edge are seen in all the spectra. The intensity of $6 \mathrm{eV}$ satellite for $\mathrm{Ni}-\mathrm{Mg}$ 
films and $\mathrm{Mg}_{2} \mathrm{Ni}$ are reduced by a factor of five compared to pure Ni film. Recently Dhesi et al. ${ }^{19,20}$ assigned these satellites to transitions to triplet $(3 \mathrm{eV})$ and singlet $(6 \mathrm{eV})$ states of the final $2 \mathrm{p}^{5} 3 \mathrm{~d}^{9}$ configuration, split by the core-valence exchange interaction (multiplet effects). The singlet state can be reached from the triplet $3 \mathrm{~d}^{8}$ initial state by spin-flip transitions due to the $2 \mathrm{p}$ spin-orbit interaction. More recently, Nesvizhskii et $a l{ }^{21}$ based on one-electron multiple scattering and atomic multiplet calculations claimed that the effect of spin-flip transition is negligible and hence the $6 \mathrm{eV}$ satellite is predominantly due to multiple scattering effect, but that the multiplet explanation of Dhesi et al. ${ }^{19,20}$ is applicable for the $3 \mathrm{eV}$ satellite. The reduced intensity for the $6 \mathrm{eV}$ satellite observed for $\mathrm{Ni}-\mathrm{Mg}$ films in the present study is therefore attributed to a decreased multiple scattering due to the presence of $\mathrm{Mg}$ and the amorphous character of the films.

Spectra were recorded at both $\mathrm{Mg} \mathrm{K}$ and Ni L-edges during hydrogen loading of films. $\mathrm{Ni} \mathrm{L}_{3,2}$ spectra of $\mathrm{Ni}_{0.24} \mathrm{Mg}_{0.76} \mathrm{H}_{\mathrm{x}}$ at different exposure times are presented in Figure 2. The spectrum denoted as 'end of hydrogenation' was recorded after exposure to hydrogen for $24 \mathrm{~h}$. Further exposure produced no changes in the spectrum. $\mathrm{H}_{2}$ absorption led to a shift towards higher energy and an enhancement in intensity. The extent of both effects depended upon exposure time and $\mathrm{Ni}: \mathrm{Mg}$ ratio. The time required to reach saturation, corresponding to the optical switching from mirror state to maximum transparency, also depended on the film thickness. Figure 3 shows $\mathrm{Ni} \mathrm{L}_{3,2}$ spectra for a $\mathrm{Ni}_{0.24} \mathrm{Mg}_{0.76}$ film as-deposited, fully hydrogenated and dehydrogenated by exposure to air for $24 \mathrm{~h}$. The hydrogen is apparently not completely removed under these conditions.

The full width at half maximum (FWHM) and integrated area for each band was obtained by fitting the Ni L-edge spectra with Gaussian functions. To exclude the edge jump, asymmetric double sigmoidal functions were also included in the fits. The results, along with branching ratios $\beta_{R}=A_{3} /\left(A_{3}+A_{2}\right)$, total integrated intensity $\left(A_{3}+A_{2}\right)$, and intensity ratio $\left(\mathrm{A}_{3} / \mathrm{A}_{2}\right)$, are given in Table II. It has been shown that, due to changes in the final state energies, $\mathrm{Ni} \mathrm{L}_{3,2}$ transitions shift towards higher energy by about $1 \mathrm{eV}$ for each unit increase in oxidation state. ${ }^{22-25}$ Since the integrated intensity $\left(\mathrm{A}_{3}+\mathrm{A}_{2}\right)$ is a ground state property, it is a quantitative and a direct measure of $3 \mathrm{~d}$ shell vacancies $\left(\mathrm{n}_{\mathrm{h}}\right){ }^{16,19,22,24}$ Further, the initial state $3 d$ spin-orbit coupling and the overlap of $2 p$ and $3 d$ wave 
functions, the so called multiplet effects, are said to affect the branching ratio $\left(\beta_{\mathrm{R}}\right){ }^{26,27}$ Another report, however, maintains that multiplet effects dominate all other interactions. ${ }^{28}$ Recent reports demonstrate that one can distinguish the nature of spin states, viz., low spin and high spin for a given oxidation state of $\mathrm{Ni}$, based on the branching ratios $\left(\beta_{\mathrm{R}}\right)$ of $\mathrm{L}_{3,2}$-edges. ${ }^{23-25}$

In the present study, the energy separation $\left(\mathrm{E}_{3}-\mathrm{E}_{2}\right)$ between the $\mathrm{L}_{3}$ and $\mathrm{L}_{2}$-edges, which is due to $2 \mathrm{p}$ spin-orbital splitting, for all the samples is found to be $\sim 17.3 \mathrm{eV}$ in accordance with earlier reports. ${ }^{15,16,19}$ The transition energies (E) for both $\mathrm{L}_{3,2}$-edges of a $\mathrm{Ni}$ film and Ni-Mg films in the metallic state show a small trend towards higher energy from pure $\mathrm{Ni}$ film to very $\mathrm{Mg}$-rich $\left(\mathrm{Ni}_{0.13} \mathrm{Mg}_{0.87}\right)$. The spectral profile and branching ratio for pure Ni film are in good agreement with the pervious reports on bulk Ni metal and for Ni films grown on $\mathrm{Cu}(001)$ and $\mathrm{Co} / \mathrm{Cu}(001){ }^{16,19}$ The Ni film was therefore utilized as a reference for Ni-Mg films. The total integrated intensity $\left(A_{3}+A_{2}\right)$ is smaller and, the $\beta_{R}$ and $\mathrm{A}_{3} / \mathrm{A}_{2}$ are larger for $\mathrm{Ni}-\mathrm{Mg}$ than for Ni (Table II). These results suggest that the addition of $\mathrm{Mg}$ produces structural changes and modification of $\mathrm{Ni}$ electronic states. Similar results were reported for $\mathrm{Ni}$ film on $\mathrm{Cu}(001)$ and $\mathrm{Co} / \mathrm{Cu}(001)$ due to charge transfer to $\mathrm{Ni}^{16,19}$

Hydrogen uptake by Ni-Mg films caused the transition energies for both $\mathrm{L}_{3,2^{-}}$ edges to shift significantly towards higher energy, by $\sim 2.3 \mathrm{eV}$ for $\mathrm{Ni}_{0.33} \mathrm{Mg}_{0.67}$ and $\sim 2.6 \mathrm{eV}$ for $\mathrm{Ni}_{0.13} \mathrm{Mg}_{0.87}$. The total integrated intensity and FWHM also increase. The values for $\beta_{R}$ and $A_{3} / A_{2}$ are comparable to those for the Ni film. In general, the effective charge transfer from metal to hydrogen is reported to be less for metal hydrides than for halides, oxides, etc. where the charge transfer is much greater. ${ }^{29,30}$ This is supported by the values of $\beta_{R}$ and $A_{3} / A_{2}$ for Ni-Mg films in the hydride state, which are comparable to those for the $\mathrm{Ni}$ film, indicating that although $\mathrm{Ni}$ is in a higher oxidation state, the effective charge transfer in the hydride is less than in the metal. The values of $\beta_{R}$ suggest that $\mathrm{Ni}$ in hydrided $\mathrm{Ni}-\mathrm{Mg}$ films is in a high-spin state. ${ }^{23-25}$ Hydriding also leads to the creation of non-equivalent Ni sites, which result in larger FWHMs. 


\section{$M g$ K-edge NEXAFS}

Mg K near-edge transmission mode spectra of a pure Mg film $(270 \mathrm{~nm})$ and two extreme compositions of Ni-Mg films in $\mathrm{He}$ and in $4 \% \mathrm{H}_{2}$ are shown in Fig. 4. The $\mathrm{Mg}$ $\mathrm{K}$-edge is shifted to lower energy for Ni-Mg films in the metallic state $(1302.2 \mathrm{eV})$ compared to pure $\mathrm{Mg}$ film $(1303.0 \mathrm{eV})$. The intensity of the spectral profile at $1304.5 \mathrm{eV}$ decreases for $\mathrm{Ni}$ rich $\mathrm{Ni}_{0.33} \mathrm{Mg}_{0.67}$ film when compared to $\mathrm{Mg}$ rich $\mathrm{Ni}_{0.33} \mathrm{Mg}_{0.67}$ and pure $\mathrm{Mg}$ films. Spectra reported for magnesium halides, magnesium oxide, and $\mathrm{Mg}$ in minerals and disordered systems show not only a sharp near-edge peak at $\sim 1310 \mathrm{eV}$ due to the $1 \mathrm{~s}$ to $3 \mathrm{p}$ transition whose intensity depends on the degeneracy of the $3 p$ states but also this feature shifts towards higher energy with increasing coordination around $\mathrm{Mg} .{ }^{31-}$ ${ }^{35}$ In the present study, the transition at $1304.5 \mathrm{eV}$ in pure $\mathrm{Mg}$ and $\mathrm{Ni}-\mathrm{Mg}$ films is assigned to $\mathrm{Mg} 1 \mathrm{~s}$ to $3 \mathrm{p}$. The edge shift towards lower energy and reduction in the intensity of the peak with increasing nickel content suggest that the coordination around $\mathrm{Mg}$ decreases, resulting in lowering of $3 \mathrm{p}$ degeneracy.

The NEXAFS total fluorescence yield (TFY) spectra for the pure $\mathrm{Mg}$ film (270 nm), for $\mathrm{Mg}_{2} \mathrm{Ni}$ and $\mathrm{MgH}_{2}$ powder samples, and a transmission mode spectrum of a thin $\mathrm{Mg}$ film $(45 \mathrm{~nm})$ in the presence of $\mathrm{He}$ and $4 \% \mathrm{H}_{2}$ are shown in Figure 5. The similarity in the spectral profiles and edge positions for $\mathrm{Mg}_{2} \mathrm{Ni}$ and the $\mathrm{Ni}_{0.33} \mathrm{Mg}_{0.67}$ film are consistent with Mg-Ni bonding in the film. The Mg K-edge TFY spectrum for the pure Mg film (270 nm) differs from the transmission mode spectrum (Figs. 4 and 5). Transmission measurements are bulk-sensitive, while TFY probes only to ca. $100 \mathrm{~nm}$ in depth. The TFY spectrum for the $\mathrm{Mg}$ film reflects both pure $\mathrm{Mg}$ and the $\mathrm{Mg}$-Pd interface region. Comparison with the transmission spectrum of a thinner $(45 \mathrm{~nm}) \mathrm{Mg}$ film confirms the presence of different surface and bulk compositions.

The Mg K-edge spectra shifted towards higher energy by $\sim 2.2$ and $\sim 2.9 \mathrm{eV}$ for $\mathrm{Ni}_{0.33} \mathrm{Mg}_{0.67}$ and $\mathrm{Ni}_{0.13} \mathrm{Mg}_{0.87}$, respectively, when hydrogen is introduced. In addition, the transitions at higher energies due to multiple scattering resonances were significantly reduced by the presence of hydrogen, which scatters weakly due to its low mass. ${ }^{36,37}$ The spectrum of the thick Mg film showed no significant changes on exposure to $\mathrm{H}_{2}$ for $2 \mathrm{~h}$, consistent with previous observations of very slow diffusion of hydrogen in relatively thick Mg films. ${ }^{29}$ The thin Mg film, however exhibited a $3.5 \mathrm{eV}$ shift following overnight 
soaking in $4 \% \mathrm{H}_{2}$ at room temperature. This is consistent with optical properties of $\mathrm{Mg}$ film with Pd overlayer, which show that an increase in Mg thickness decreases the optical response to hydrogen exposure. ${ }^{38}$ The $\mathrm{Mg}$ K-edge TFY spectrum for bulk $\mathrm{MgH}_{2}$ also shows a shift of $\sim 2.3 \mathrm{eV}$ towards higher energy compared to the $\mathrm{Mg}$ film, consistent with the presence of divalent $\mathrm{Mg}$.

\section{Magnesium K-Edge EXAFS}

EXAFS data were analyzed using a background-subtraction method ${ }^{39-43}$ with optimization of the low $r$ portion of the EXAFS, followed by Fourier transformation to $r$ space. The normalized spectra of the $270 \mathrm{~nm} \mathrm{Mg}$ film and two $\mathrm{Ni}-\mathrm{Mg}$ films are shown in Figure 6. The magnitude of the oscillations decreased with increasing nickel concentration in as-deposited $\mathrm{Ni}-\mathrm{Mg}$ films due to disruption of the $\mathrm{Mg}$ structure. In the hydride state only very weak EXAFS oscillations were observed irrespective of $\mathrm{Ni}$ content. Comparison of EXAFS for Ni-Mg films in the hydride and metallic states with bulk $\mathrm{MgH}_{2}$ and $\mathrm{Mg}_{2} \mathrm{Ni}$ (Fig. 7) suggests that more of the magnesium in the $\mathrm{Ni}_{0.13} \mathrm{Mg}_{0.87}$ film is hydrided than in the $\mathrm{Ni}_{0.33} \mathrm{Mg}_{0.67}$ film, where unreacted $\mathrm{Mg}_{2} \mathrm{Ni}$ remains. To get more insight into the structural properties of $\mathrm{Ni}-\mathrm{Mg}$ thin films, detailed analyses of the experimental EXAFS spectra were conducted by theoretical fits.

Scattering amplitudes and phase shift functions of the $\mathrm{Mg}-\mathrm{Mg}, \mathrm{Mg}-\mathrm{Ni}$, and $\mathrm{Mg}-\mathrm{O}$ pairs in $\mathrm{Mg}, \mathrm{Mg}_{2} \mathrm{Ni}$ and $\mathrm{MgO}$ were calculated using the program FEFF (7.02). ${ }^{40,41} \mathrm{The}$ FEFFIT $(2.5 d),{ }^{42}$ which is based on a nonlinear least squares technique was used to fit the experimental $r$ space EXAFS data. Phase-corrected Fourier transforms of $\chi(k)$ to $r$ space with a $k^{2}$ weighting factor and a Hanning window function $(D k 1$ and $D k 2=0.1)$ were performed using values of $\mathrm{K}_{\min }, \mathrm{K}_{\max }, \mathrm{r}_{\min }$, and $\mathrm{r}_{\min }$ of $1.8 \AA^{-1}, 5.6 \AA^{-1}, 2.1 \AA$ and $5.1 \AA$, respectively. The value of the passive electron reduction factor $\left(S_{0}^{2}\right)^{43}$ was deduced from the spectrum of $\mathrm{MgO}$ and used for fitting Ni-Mg film spectra.

The Fourier transformed $\mathrm{k}^{2}$-weighted $\mathrm{Mg} \mathrm{K}$-edge EXAFS intensities for Ni-Mg films in their metallic states are presented in Figure 8 along with theoretical fits. Figure 9 shows the fitting results in $\mathrm{k}$ space. The resultant structural parameters, coordination number $(\mathrm{N})$, bond distance $(\mathrm{R})$ and Debye-Waller factor $\left(\sigma^{2}\right)$ for $\mathrm{Mg}, \mathrm{Ni}_{0.13} \mathrm{Mg}_{0.87}$ and $\mathrm{Ni}_{0.33} \mathrm{Mg}_{0.67}$ are given in Table III. Attempts were made to fit the data using $\mathrm{Mg}-\mathrm{Mg}$ (first 
and second shell), $\mathrm{Mg}-\mathrm{Ni}$ and $\mathrm{Mg}-\mathrm{O}$ interactions. No significant contributions from $\mathrm{Mg}-$ $\mathrm{Ni}$ and $\mathrm{Mg}-\mathrm{O}$ were found. There is a decrease in amplitude of the Fourier-transformed intensity on the addition of nickel. The nearest neighbor and next nearest neighbor $\mathrm{Mg}$ $\mathrm{Mg}$ shells experience a decrease in mean square relative displacement (MSRD) with increasing nickel concentration. Although the Ni-Mg films are amorphous by XRD, there is microscopic ordering up to the second shell $(\sim 4.5 \AA)$, despite decreased coordination numbers and increases disorder with increasing Ni concentration.

Attempts to fit the EXAFS data for Ni-Mg films in the hydride states failed due to high signal to noise ratios and weak EXAFS oscillations due to the presence of hydrogen as nearest neighbor. The weak EXAFS oscillations in $\mathrm{k}$ space for $\mathrm{Ni}-\mathrm{Mg}$ films in hydride state were therefore compared with reference materials $\mathrm{MgH}_{2}$ and $\mathrm{Mg}_{2} \mathrm{Ni}$ (Fig. 10).

The hydrided $45 \mathrm{~nm} \mathrm{Mg}$ film shows the features similar to those in bulk $\mathrm{MgH}_{2}{ }^{6,7}$ Hydrided Ni-Mg films, however, do not resemble bulk $\mathrm{MgH}_{2}$. Instead, $\mathrm{Ni}_{0.13} \mathrm{Mg}_{0.87}$ and $\mathrm{Ni}_{0.33} \mathrm{Mg}_{0.67}$ in both metallic and hydrides state look more like $\mathrm{Mg}_{2} \mathrm{Ni}$. This suggests that the $\mathrm{Ni}-\mathrm{Mg}$ films contain some $\mathrm{Mg}_{2} \mathrm{Ni}$, which dominates the $\mathrm{Mg}$ EXAFS spectrum and that this phase persists even when the free magnesium is converted to its hydride. These results are also consistent with the lower transparency of films with higher Ni content. A relatively small amount of $\mathrm{Ni}(\sim 10 \mathrm{~mol} \%)$ is sufficient to facilitate absorption of $\mathrm{H}_{2}$. 


\section{Conclusions}

The co-sputtered Ni-Mg films were amorphous. The presence of nickel led to increased disorder and decreased coordination around both $\mathrm{Ni}$ and $\mathrm{Mg}$ compared to pure metal films. Introducing $\mathrm{H}_{2}$ into $\mathrm{Ni}-\mathrm{Mg}$ films resulted in the formation of $\mathrm{Mg}-\mathrm{Ni}$ and $\mathrm{Mg}$ hydrides, with significant positive edge shifts. The presence of hydrogen as a near neighbor around $\mathrm{Mg}$ produced a drastic reduction in the intensities of multiple scattering resonances at higher energies. The extent of hydriding depended on the Ni-Mg ratio. A thin pure $\mathrm{Mg}$ film also was converted to $\mathrm{MgH}_{2}$. Although the absorption was much slower without nickel, the extent of hydriding was greater. Addition of $\mathrm{Ni}$ led to an increase in optical switching speed, a decrease in maximum optical transparency, and a decrease in $\mathrm{Mg}$ utilization, probably due to the presence of unreacted $\mathrm{Mg}_{2} \mathrm{Ni}$. Opimization of switching speed and desired transmittance and reflectance ranges requires adjustment both of the $\mathrm{Ni}-\mathrm{Mg}$ ratio and film thickness.

\section{Acknowledgements}

This work was supported by the Assistant Secretary for Energy Efficiency and Renewable Energy, Office of Building Technology, State and Community Programs, Office of Building Research and Standards of the U.S. Department of Energy under Contract No. DE-AC03-76SF00098. The Advanced Light Source is operated by the

Director, Office of Science, Office of Basic Energy Sciences, Division of Materials Science of US Department of Energy under Contract No. DE-AC03-76SF00098 at LBNL. Financial support from the National Science Foundation under contract NevadaNSF-EPSCoR is gratefully acknowledged. 


\section{References}

${ }^{1}$ J. N. Huiberts, R. Griessen, J. H. Rector, R. J. Wijngaarden, J. P. Dekker, D. G. de Groot, and N. J. Koeman, Nature (London) 380, 231 (1996).

${ }^{2}$ R. Griessen, Europhysics News 32, 40 (2001).

${ }^{3}$ P. van der Sluis, M. Ouwerkerk, and P. A. Duine, Appl. Phys. Lett. 70, 3356 (1997).

${ }^{4}$ T. J. Richardson, J. L. Slack, R. D. Armitage, R. Kostecki, B. Farangis, and M. D. Rubin, Appl. Phys. Lett. 78, 3047 (2001).

${ }^{5}$ T. J. Richardson, J. L. Slack, B. Farangis, and M. D. Rubin, Appl. Phys. Lett. 80, 1349 (2002).

${ }^{6}$ K. Higuchi , H. Kajioka , K. Toiyama , H. Fujii , S. Orimo , and Y. Kikuchi, J. Alloys and Compds. 293-5, 484 (1999).

${ }^{7}$ K. Yamamoto , K. Higuchi , H. Kajioka , H. Sumida , S. Orimo , and H. Fujii, J. Alloys and Compds. 330-2, 352 (2002).

${ }^{8}$ J. Stöhr, NEXAFS Spectroscopy, (Springer, New York, 1992),

${ }^{9}$ J. G. Chen, Surf. Sci. Rep. 30, 1 (1997).

${ }^{10}$ F. M. F. de Groot, Chem. Rev. 101, 1779 (2001).

${ }^{11}$ D. Wang, A. J. Freeman, and H. Krakauer, Phys. Rev. B 26, 1340 (1982).

${ }^{12}$ J. Tersoff and L. M. Falicov, Phys. Rev. B 26, 6186 (1982).

${ }^{13}$ O. Eriksson, A. M. Boring, R. C. Albers, G. W. Fernando, and B. R. Copper, Phys. Rev. B 45, 2868 (1992).

${ }^{14}$ O. Hjortstam, J. Trygg, J. M. Wills, B. Johansson, and O. Eriksson, Phys. Rev. B 53, 9204 (1996).

${ }^{15}$ S. S. Dhesi, E. Dudzik, H. A. Dürr, G. van der Lann, and N. B. Brookes, J. Appl. Phys. 87, 5466 (2000).

${ }^{16}$ P. Srivastava, N. Haack, H. Wende, R. Chauvistré, and K. Baberschke, Phys. Rev. B 56, R4398 (1997).

${ }^{17}$ J. H. Underwood and E. M. Gullikson, J. Eelctron Spectrosc. Relat. Phenom. 92, 265 (1998).

${ }^{18}$ X-ray Data Booklet, LBNL/PUB490 Rev. 2 (2001). 
${ }^{19}$ S. S. Dhesi, H. A. Dürr, G. van der Lann, E. Dudzik, and N. B. Brookes, Phys. Rev. B 60, 12852 (1999).

${ }^{20}$ S. S. Dhesi, E. Dudzik, H. A. Dürr, N. B. Brookes, and G. van der Laan, Surf. Sci. 4546, 930 (2000).

${ }^{21}$ A. I. Nesvizhskii, A. L. Ankudinov, J. J. Rehr, and K. Baberschke Phys. Rev. B 62, 15295 (2000).

${ }^{22}$ H. Wang, P. Ge, C. G. Riordan, S. Brooker, C. G. Woomer, T. Collins, C. A. Melendres, O. Graudejus, N. Bartlett, and S. P. Cramer, J. Phys. Chem. B 102, 8343 (1998).

${ }^{23}$ H. Wang, C. Y. Ralston, D. S. Patil, R. M. Jones, W. Gu, M. Verhagen, M. Adams, P. Ge, C. Riordan, C. A. Marganian, P. Mascharak, J. Kovacs, C. G. Miller, T. J. Collins, S. Brooker, P. D. Croucher, K. Wang, E. I. Stiefel, and S. P. Cramer, J. Am. Chem. Soc. 122, 10544 (2000).

${ }^{24}$ H. Wang, D. S. Patil, W. Gu, L. Jacquamet, S. Friedrich, T. Funk, and S. P. Cramer, J. Electron Spectrosc. Relat. Phenom. 114-6, 855 (2001).

${ }^{25}$ C. Y. Ralston, H. Wang, S. W. Ragsdale, M. Kumar, N. J. Spangler, P. W. Ludden, W. Gu, R. M. Jones, D. S. Patil, and S. P. Cramer, J. Am. Chem. Soc. 122, 10553 (2000).

${ }^{26}$ B. T. Thole and G. van der Lann, Phys. Rev. B 38, 3158 (1988).

${ }^{27}$ G. van der Lann and B. T. Thole, Phys. Rev. Lett. 60, 1977 (1988).

${ }^{28}$ F. M. F. de Groot, Physica B 208-9, 15 (1995).

${ }^{29}$ M. Gupta and L. Schlapbach, Hydrogen in Intermetallic Compounds I, edited by L. Schlapbach (Springer, Berlin, 1988), Chap. 6.

${ }^{30}$ R. Yu and P. K. Lam, Phys. Rev. B 37, 8730 (1988).

${ }^{31}$ S. Naoé, T. Murata, and T. Matsukawa, Physica B 158, 615 (1989).

${ }^{32}$ T. Yoshida, T. Tanaka, H. Yoshida, T. Funabiki, and S. Yoshida, J. Phys. Chem. 100, 2302 (1996).

${ }^{33}$ H. Aritani, T. Tanaka, T. Funabiki, S. Yoshida, M. Kudo, and S. Hasegawa, J. Phys. Chem. 100, 5440 (1996).

${ }^{34}$ H. Aritani, H. Yamada, T. Nishio, T. Shiono, S. Imamura, M. Kudo, S. Hasegawa, T. Tanaka, and S. Yoshida, J. Phys. Chem. 104, 10133 (2000). 
${ }^{35} \mathrm{Ph}$. Ildefonse, G. Calas, A. M. Flank, and P. Lagarde, Nucl. Instr. and Meth. in Phys. Res. B 97, 172 (1995).

${ }^{36}$ R R. G. Agostino, G. Liberti, V. Formoso, E. Colavita, A. Züttel, C. Nützenadel, L. Schlapbach A. Santaniello, and C. Gauthier, Phys. Rev. B 61, 13647 (2000).

${ }^{37}$ B. Lengeler, Phys. Rev. Lett. 53, 74 (1984).

${ }^{38}$ T. J. Richardson et al., unpublished.

${ }^{39}$ M. Newville, P. Livins, Y. Yacoby, J. J. Rehr, and E. A. Stern, Phys. Rev. B 47, 14126 (1993).

${ }^{40}$ A. L. Ankudinov and J. J. Rehr, Phys. Rev. B 56, R1712 (1997).

${ }^{41}$ A. L. Ankudinov, Ph.D. thesis, University of Washington, 1996.

${ }^{42}$ E. A. Stern, M. Newville, B. D. Ravel, Y. Yacoby, and D. Haskel, Physica B 208-9, 117 (1995).

${ }^{43}$ E. A. Stern and S. M. Heald, in Handbook on Synchrotron Radiation, edited by E. E. Koch (North-Holland, New York, 1983), Vol. 1. 
Table I. Ni-Mg Film and Pd over-layer thicknesses and compositions.

\begin{tabular}{cccc}
\hline Sample & $\begin{array}{c}\text { Film thickness } \\
(\mathrm{nm})\end{array}$ & $\begin{array}{c}\text { Pd over-layer } \\
\text { thickness }(\mathrm{nm})\end{array}$ & Composition \\
\hline Ni128_1 & 100 & 20 & $\mathrm{Ni}$ \\
NiMg130_2 & 154 & 11 & $\mathrm{Ni}_{0.33} \mathrm{Mg}_{0.67}$ \\
NiMg130_3 & 172 & 11 & $\mathrm{Ni}_{0.25} \mathrm{Mg}_{0.75}$ \\
NiMg130_4 & 218 & 11 & $\mathrm{Ni}_{0.17} \mathrm{Mg}_{0.83}$ \\
NiMg130_5 & 232 & 11 & $\mathrm{Ni}_{0.13} \mathrm{Mg}_{0.87}$ \\
NiMg129_3 & 262 & 22 & $\mathrm{Ni}_{0.24} \mathrm{Mg}_{0.76}$ \\
Mg131_5 & 270 & 10 & $\mathrm{Mg}$ \\
Mg152_1 & 45 & 10 & $\mathrm{Mg}$ \\
\hline \hline
\end{tabular}


Table II. Transition energies (E), integrated areas (A), full width at half maximum (FWHM), branching ratios, $\beta_{\mathrm{R}}=\mathrm{A}_{3} /\left(\mathrm{A}_{3}+\mathrm{A}_{2}\right)$, total integrated intensities, $\left(\mathrm{A}_{3}+\mathrm{A}_{2}\right)$ and intensity ratios $\left(\mathrm{A}_{3} / \mathrm{A}_{2}\right)$ for $\mathrm{Ni} \mathrm{L}_{3,2}$-edge XRAS of $(\mathrm{A}) \mathrm{Ni}(\mathrm{B} \& \mathrm{E}) \mathrm{Ni}_{0.33} \mathrm{Mg}_{0.67}(\mathrm{C} \& \mathrm{~F})$ $\mathrm{Ni}_{0.13} \mathrm{Mg}_{0.87}$ and (D) $\mathrm{Mg}_{2} \mathrm{Ni}$.

\begin{tabular}{|c|c|c|c|c|c|c|c|c|}
\hline \multirow{2}{*}{$\begin{array}{l}\text { Sam } \\
\text { ple }\end{array}$} & \multicolumn{2}{|c|}{$\mathrm{L}_{3}$} & \multicolumn{2}{|c|}{$\mathrm{L}_{2}$} & \multirow{2}{*}{$\begin{array}{c}\text { FWHM } \\
(\mathrm{eV})\end{array}$} & \multirow[t]{2}{*}{$\beta_{R}$} & \multirow{2}{*}{$\begin{array}{c}A_{3}+A_{2} \\
\text { (a.u.) }\end{array}$} & \multirow[t]{2}{*}{$\left(\mathrm{A}_{3} / \mathrm{A}_{2}\right)$} \\
\hline & $\mathrm{E}_{3}(\mathrm{eV})$ & $\mathrm{A}_{3}$ (a.u.) & $\mathrm{E}_{2}(\mathrm{eV})$ & $\mathrm{A}_{2}$ (a.u.) & & & & \\
\hline $\mathrm{A}^{\dagger}$ & 853.5 & 2.02 & 870.8 & 0.66 & 3.1 & 0.754 & 2.68 & 3.06 \\
\hline $\mathrm{B}^{\dagger}$ & 853.7 & 0.88 & 871.0 & 0.20 & 2.0 & 0.816 & 1.08 & 4.40 \\
\hline $\mathrm{C}^{\dagger}$ & 853.9 & 1.01 & 871.1 & 0.19 & 2.3 & 0.840 & 1.2 & 5.32 \\
\hline $\mathrm{D} \neq$ & 853.2 & 1.70 & 870.3 & 0.37 & 3.2 & 0.821 & 2.07 & 4.60 \\
\hline $\mathrm{E}^{*}$ & 856.0 & 2.55 & 873.4 & 0.81 & 3.9 & 0.758 & 3.36 & 3.15 \\
\hline $\mathrm{F}^{*}$ & 856.5 & 3.07 & 873.9 & 0.99 & 3.6 & 0.757 & 4.06 & 3.10 \\
\hline
\end{tabular}

${ }^{\dagger}$ XAS measured in transmission mode in He atmosphere.

\$ Total fluorescence yield (TFY) under vacuum.

* XAS measured in transmission mode in $4 \% \mathrm{H}_{2}$ in $\mathrm{He}$ atmosphere. 
Table III. Coordination numbers $\left(N_{M g}\right)$, bond distances $\left(R_{M g-M g}\right)$, and Debye-Waller factors $\left(\sigma_{M g-M g}^{2}\right.$ ) obtained from $M g K$-edge EXAFS for thin films in metallic state.

\begin{tabular}{ccccccc}
\hline \hline & \multicolumn{3}{c}{$\mathrm{Mg}-\mathrm{Mg}$ (first shell) } & \multicolumn{3}{c}{$\mathrm{Mg}-\mathrm{Mg}$ (second shell) } \\
Sample & $\mathrm{N}$ & $\mathrm{R}(\AA)$ & $\sigma^{2}\left(10^{-2} \AA^{2}\right)$ & $\mathrm{N}$ & $\mathrm{R}(\AA)$ & $\sigma^{2}\left(10^{-2} \AA^{2}\right)$ \\
\hline $\mathrm{Mg}$ & $12.00(66)$ & $3.203(3)$ & $2.21(19)$ & $4.92(97)$ & $4.568(24)$ & $2.63(19)$ \\
$\mathrm{Ni}_{0.13} \mathrm{Mg}_{0.87}$ & $8.60(17)$ & $3.098(1)$ & $2.75(7)$ & $2.92(25)$ & $4.465(11)$ & $3.27(7)$ \\
$\mathrm{Ni}_{0.33} \mathrm{Mg}_{0.67}$ & $3.33(39)$ & $3.038(6)$ & $1.65(35)$ & $1.70(57)$ & $4.472(35)$ & $1.96(35)$ \\
\hline \hline
\end{tabular}




\section{Figure Captions}

1. Ni $\mathrm{L}_{3,2}$-edge transmission mode NEXAFS spectra of thin films measured in He: (a) pure $\mathrm{Ni}$, (b) $\mathrm{Ni}_{0.33} \mathrm{Mg}_{0.67}$ and (c) $\mathrm{Ni}_{0.13} \mathrm{Mg}_{0.87}$; in $4 \% \mathrm{H}_{2}$ in $\mathrm{He}$ (e) $\mathrm{Ni}_{0.33} \mathrm{Mg}_{0.67}$ and (f) $\mathrm{Ni}_{0.13} \mathrm{Mg}_{0.87}$. Spectrum (d) $\mathrm{Mg}_{2} \mathrm{Ni}$ measured by total fluorescence yield in vacuum. The $6 \mathrm{eV}$ satellite is indicated by arrow. All spectra were normalized to the background. Baselines were shifted for clarity of presentation.

2. Transmission mode $\mathrm{Ni} \mathrm{L}_{3,2}$-edge NEXAS spectra of $\mathrm{Ni}_{0.24} \mathrm{Mg}_{0.76}$ thin film measured in $\mathrm{He}$ (denoted as 'virgin') and in $4 \% \mathrm{H}_{2}$ in $\mathrm{He}$ (all other curves) as a function of time. The curve denoted as 'end of hydrogenation' was recorded after $24 \mathrm{~h}$ exposure.

3. Transmission mode $\mathrm{Ni} \mathrm{L}_{3,2}$-edge NEXAS spectra of $\mathrm{Ni}_{0.24} \mathrm{Mg}_{0.76}$ thin film in $\mathrm{He}$ (solid line), in $4 \% \mathrm{H}_{2}$ after prolonged hydrogenation (dashed line), and in He after 1 day in air (dotted line).

4. Transmission mode Mg K-edge NEXAFS spectra of thin films in $\mathrm{He}$ : (a) $\mathrm{Mg}$, (b) $\mathrm{Ni}_{0.13} \mathrm{Mg}_{0.87}$, (c) $\mathrm{Ni}_{0.33} \mathrm{Mg}_{0.67}$; in $4 \% \mathrm{H}_{2}$ in He: (d) $\mathrm{Ni}_{0.13} \mathrm{Mg}_{0.87}$ and (e) $\mathrm{Ni}_{0.33} \mathrm{Mg}_{0.67}$.

5. Mg K-edge NEXAFS spectra of: (a) Mg $270 \mathrm{~nm}$ (TFY), (b) Mg $45 \mathrm{~nm}$ (transmission in $\mathrm{He}$ ), (c) $\mathrm{Mg}_{2} \mathrm{Ni}$ (TFY), (d) $\mathrm{MgH}_{2}$ (TFY), and (e) $\mathrm{Mg} 45 \mathrm{~nm}$ (transmission in $4 \% \mathrm{H}_{2}$ in $\mathrm{He})$.

6. Mg K-edge EXAFS spectra of thin films measured by transmission in $\mathrm{He}$ (a) $\mathrm{Mg}$, (b) $\mathrm{Ni}_{0.13} \mathrm{Mg}_{0.87}$, (c) $\mathrm{Ni}_{0.33} \mathrm{Mg}_{0.67}$; in $4 \% \mathrm{H}_{2}$ in $\mathrm{He}$ : (d) $\mathrm{Ni}_{0.13} \mathrm{Mg}_{0.87}$, (e) $\mathrm{Ni}_{0.33} \mathrm{Mg}_{0.67}$.

7. Mg K-edge EXAFS spectra of: (a) Mg $270 \mathrm{~nm}$ (transmission in He), (b) $\mathrm{Mg} 45 \mathrm{~nm}$ (transmission in $\mathrm{He}$ ), (c) $\mathrm{Mg}_{2} \mathrm{Ni}$ (TFY), (d) $\mathrm{MgH}_{2}$ (TFY), and (e) $\mathrm{Mg} 45 \mathrm{~nm}$ (transmission in $4 \% \mathrm{H}_{2}$ in $\mathrm{He}$ ).

8. Phase corrected and Fourier transformed Mg K-edge EXAFS spectra of Mg, $\mathrm{Ni}_{0.13} \mathrm{Mg}_{0.87}$, and $\mathrm{Ni}_{0.33} \mathrm{Mg}_{0.67}$ thin films in the metallic state. 
9. Fit results in $\mathrm{k}$ space for $\mathrm{Mg} \mathrm{K}$-edge EXAFS spectra of $\mathrm{Mg}, \mathrm{Ni}_{0.13} \mathrm{Mg}_{0.87}$ and $\mathrm{Ni}_{0.33} \mathrm{Mg}_{0.67}$, thin films in the metallic state.

10. $\mathrm{Mg} \mathrm{K}$-edge EXAFS in k space for: (a) $\mathrm{MgH}_{2}$, (b) $\mathrm{Mg}(45 \mathrm{~nm}$ ) thin film in hydride state, (c) $\mathrm{Mg}_{2} \mathrm{Ni}$, (d) $\mathrm{Ni}_{0.13} \mathrm{Mg}_{0.87}$ in hydride state, (e) $\mathrm{Ni}_{0.33} \mathrm{Mg}_{0.67}$ in hydride, and (f) $\mathrm{Ni}_{0.33} \mathrm{Mg}_{0.67}$ in metallic state. 
Figure 1

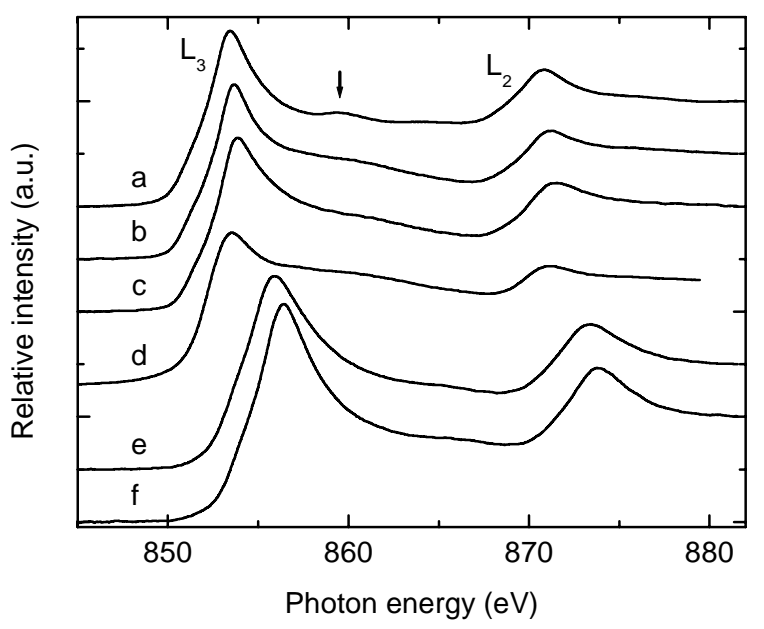


Figure 2

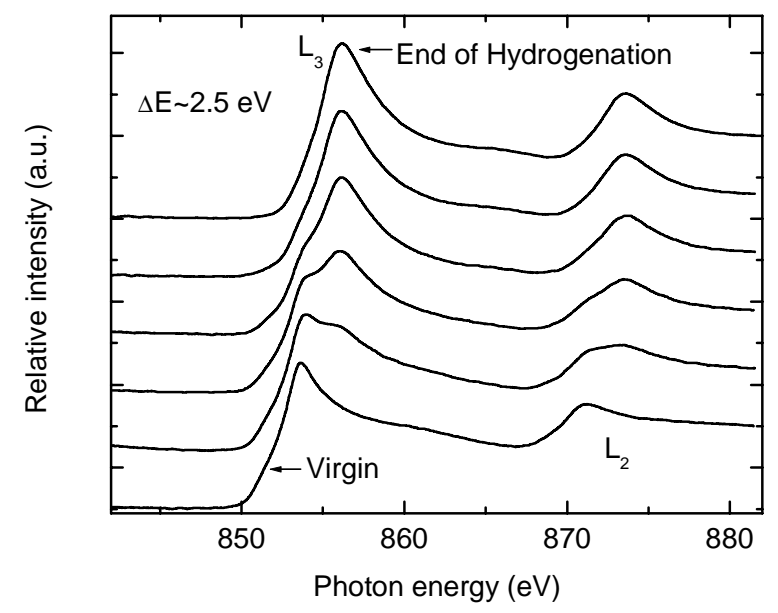


Figure 3

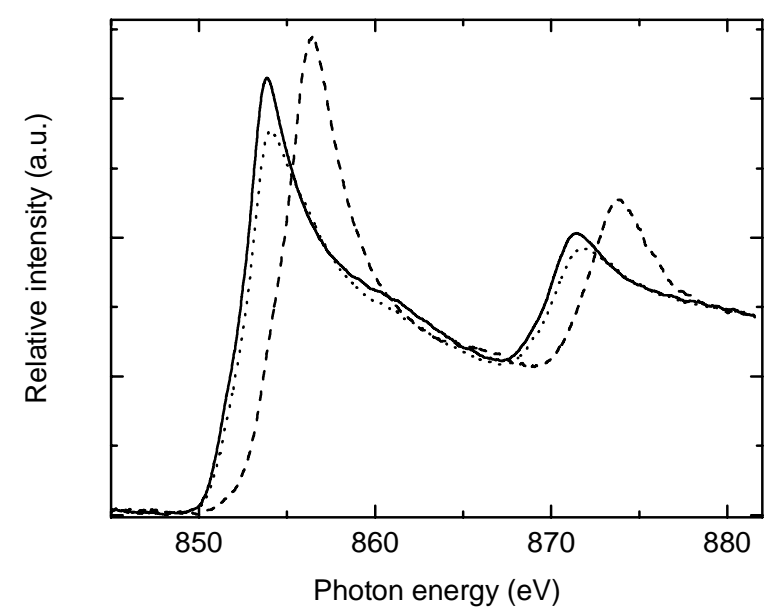


Figure 4

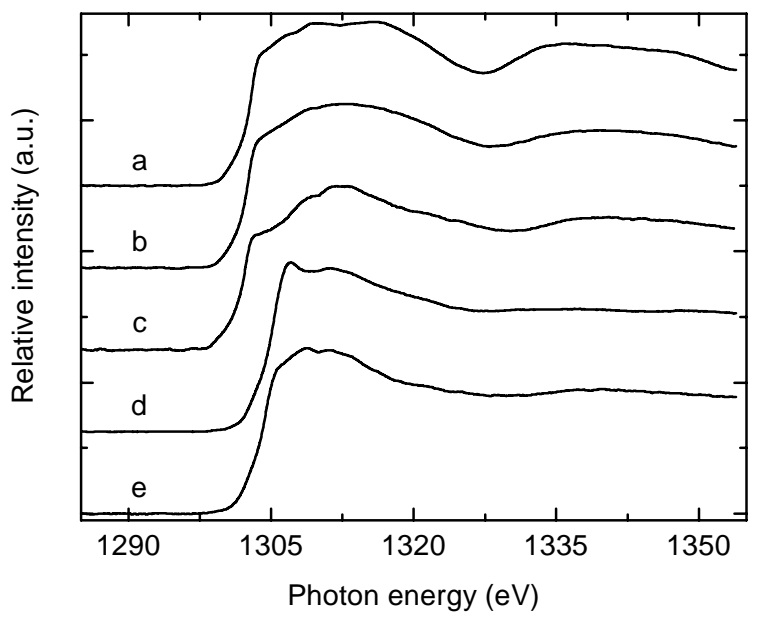


Figure 5

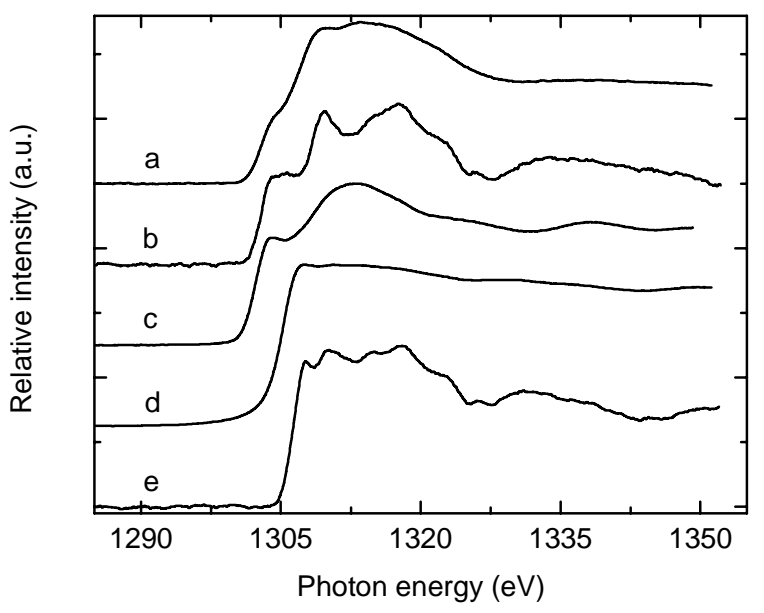


Figure 6

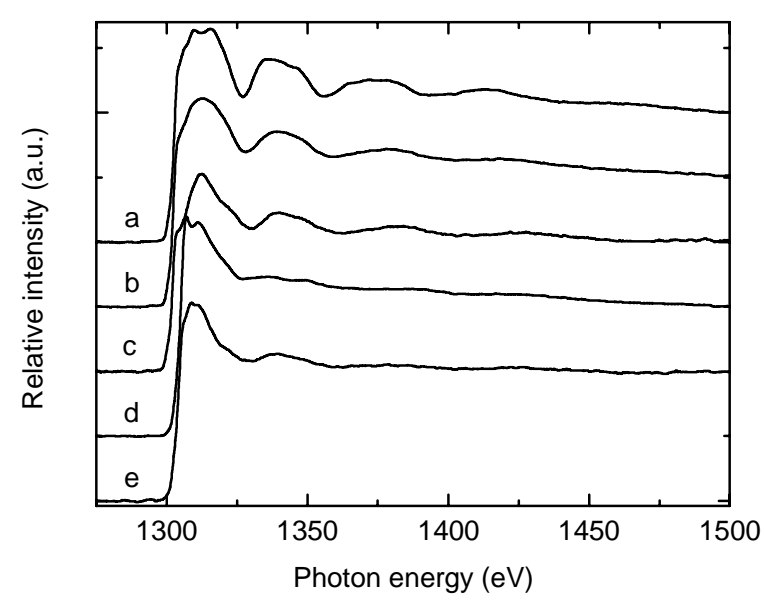


Figure 7

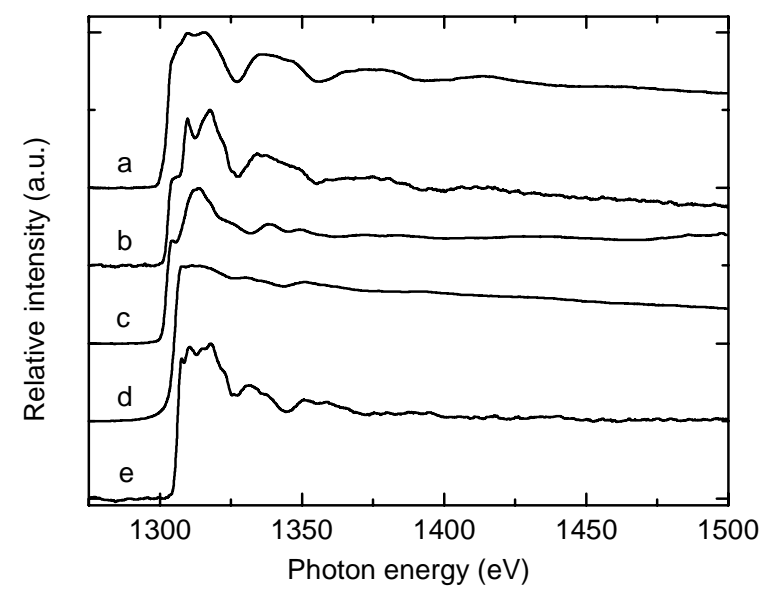


Figure 8

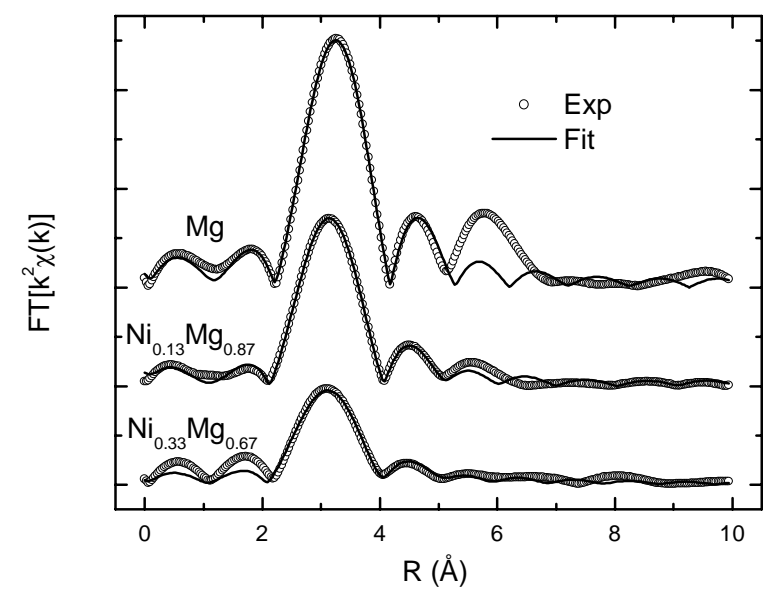


Figure 9

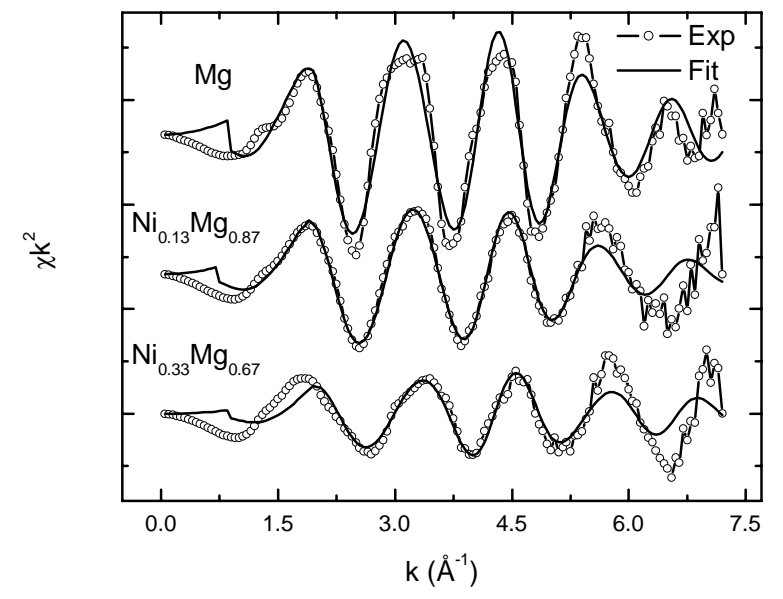


Figure 10

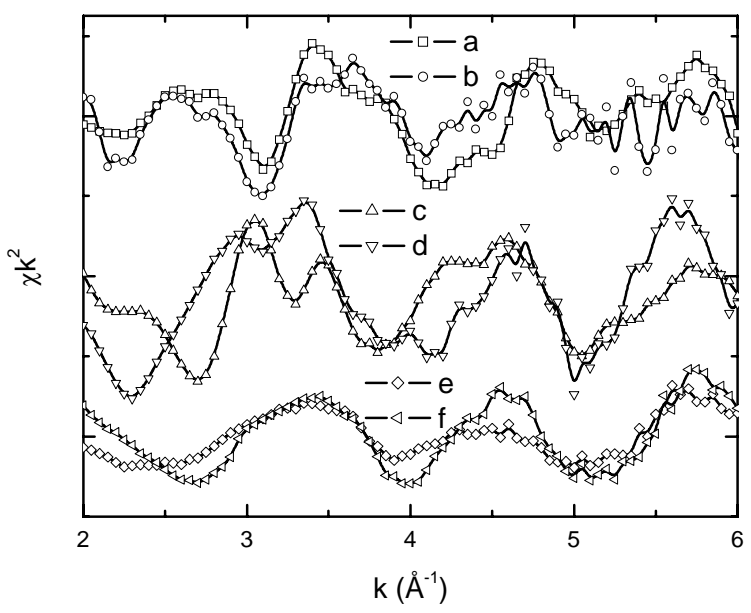

